\title{
NATURAL CLIMATE VARIABILITY DURING THE HOLOCENE
}

\author{
V A Dergachev ${ }^{1} \bullet \mathrm{O} \mathrm{M} \mathrm{Raspopov}^{2} \bullet \mathrm{F} \mathrm{Damblon}^{3} \bullet \mathrm{H} \mathrm{Jungner}^{4} \bullet \mathrm{G}$ I Zaitseva ${ }^{5}$
}

\begin{abstract}
High-precision radiocarbon age calibration for different terrestrial samples allows us to establish accurate boundaries for many climatic time series. At the same time, the fluctuations of ${ }^{14} \mathrm{C}$ content reflect solar variability. A bispectrum analysis of long-term series of the ${ }^{14} \mathrm{C}$ content deduced from decadal measurements in tree rings demonstrates the existence of amplitude modulation, with a period of main modulation of $\sim 2400 \mathrm{yr}$. In ${ }^{14} \mathrm{C}$ time series for the last $11 \mathrm{kyr}$, major oscillations are distinguished at 8.5-7.8, 5.4-4.7, 2.6-2.2, and 1.1-0.4 cal kyr BP with 2400 -yr periodicity. High amplitudes in cosmogenic isotope content with a periodicity of about $2400 \mathrm{yr}$ appear synchronous to cooling events documented in Greenland ice cores, to the timing of worldwide Holocene glacier expansion, and to the periods of lake-level changes. This paper focuses on revealing solar forcing on the Earth's climate and about the nature, significance, and impact of sharp Holocene climate variability on human societies and civilizations.
\end{abstract}

\section{INTRODUCTION}

Many extensive paleoclimatic studies over the past few decades have testified to the considerable climate fluctuations in the Holocene (see e.g. Mayewski et al. [2004] and references in this paper). To detect major periods of Holocene rapid climate change, Mayewski et al. (2004) analyzed 50 globally distributed paleoclimatic series of highly resolved samples with uncertainties in age $<500 \mathrm{yr}$. These records were smoothed with a 200 -yr Gaussian filter to make it easier to compare the highprecision samples with more roughly sampled records. They established 6 periods of significant rapid climate change during the periods $9-8,6-5,4.2-3.8,3.5-2.5$, and $0.6-0.15$ cal kyr BP.

In radiocarbon time series from tree rings, which are characteristic of the variability in solar activity for the last $11 \mathrm{kyr}$, large-scale increased amplitudes of ${ }^{14} \mathrm{C}$ content are distinguished in the time intervals at 8.5-7.8, 5.4-4.7, 2.6-2.2, and 1.1-0.4 cal kyr BP with 2400 -yr periodicity (e.g. Vasiliev and Dergachev 2002). These time intervals correspond closely with the rapid climate changes derived by Mayewski et al. (2004). Vasiliev and Dergachev (2002) analyzed the primary properties of decadal data on ${ }^{14} \mathrm{C}$ series using power spectrum, time spectrum, and bispectrum analyses. They established that the amplitudes of ${ }^{14} \mathrm{C}$ content vary periodically in time, with the changes of amplitudes being synchronous in the wide frequency band. A bispectrum analysis of the data demonstrates the existence of amplitude modulation with a period of $\sim 2400 \mathrm{yr}$. In addition, a bispectrum analysis allows us to classify 3 primary lines of the power spectrum, $710 \mathrm{yr}, 420 \mathrm{yr}$, and $210 \mathrm{yr}$, and to show that the line component corresponding to $210 \mathrm{yr}$ has first harmonics.

It should be noted that the response of the atmosphere-ocean system to solar activity and variability has a nonlinear, and hence regional, character. It immediately follows that the analysis of circulation and hydrological factors may be more representative than the analysis of temperature as a factor. Taking into account the internal variability of the climatic system, the nonlinear character of the response of the atmosphere-ocean to solar forcing may be unsteady both in time and space. Raspopov et al. (2007) considered the peculiarity of the regional response of the atmosphere-ocean system to the long-term variations of solar activity based on analyzing the results of simulation of temperature response of climatic systems to long-term solar variability. Results of the analysis indi-

\footnotetext{
${ }^{1}$ Ioffe Physico-Technical Institute, St. Petersburg, Russia. Corresponding author: Email: v.dergachev@mail.ioffe.ru.

${ }^{2}$ St. Petersburg Branch of IZMIRAN, St. Petersburg, Russia.

${ }^{3}$ Royal Institute of Natural Science, Brussels, Belgium.

${ }^{4}$ University of Helsinki, Finland.

${ }^{5}$ The Institute for the History of Material Culture, Russian Academy of Sciences, St. Petersburg, Russia.
} 
cate that there are regions of steady positive and steady negative temperature response to the strengthening of the solar signal. It is apparent that the temperature response to solar forcing in the boundary areas between these regions is unsteady or absent.

At present, we can use a vast range of archives of climatic information from tree rings, ice cores, corals, etc. As a rule, most attention has been focused on the record of temperature change. The measure of climate is not necessarily temperature; the magnitude and cause of climatic changes are detected in other climate parameters. At a regional level, in many cases it is important to consider the climatic record not only in terms of temperature but also in terms of hydrological and atmospheric circulation changes. Indeed, hydrology is more important for people than temperature variability in the most densely populated parts of the world. However, there is little systematic knowledge about the range and rate of change of hydrological and atmospheric circulation parameters.

An understanding of the mechanisms and history of natural climate variability is important for improving climate predictability and properly attributing ongoing climate changes to human and natural forcings. The general state of Earth's climate is controlled by the balance of energy on Earth received from the sun and the amount of energy released back to space. The sun provides more than $99 \%$ of the energy to Earth's climate. Causes of climate change involve any process that can alter this global energy balance. Energy from the sun drives Earth's weather and climate. A number of studies have sought to find correlations between the changes in solar activity and the temperature of Earth's atmosphere. Good correlations have been found (e.g. Eddy 1976; Reid 1987; Friis-Christensen and Lassen 1991; Solanki and Fligge 1999; Thompson et al. 2006) on a timescale of decades to centuries. The observed solar variability acts on the atmosphere through total solar irradiance variations and solar spectral irradiance variations, through solar energetic particle events, and through modulation by the solar magnetic activity cycle of the flux of both galactic cosmic rays and solar energy particles. Recent observations suggest that cosmic rays coupled with solar activity may play a key role in climate change. Satellite data have revealed a surprising correlation between cosmic ray intensity and the fraction of Earth covered by low clouds (e.g. Svensmark and Friis-Christensen 1997; Harrison and Stephenson 2005; Svensmark et al. 2007). Since the cosmic ray intensity is modulated by the solar wind, this may be an important clue to the long-sought mechanism for solar-climate variability.

Although the sun is the driver of Earth's climate and some associations have been observed between instrumental and historical records of solar activity and climate change, establishment of a convincing connection between solar variability and climate change has proved difficult. One of the problems is that while solar particle emissions and short-wave radiation change by large amounts in a solar cycle, total irradiance varies minimally and accurate measurements have only been available in the satellite era.

In this study, we give the main attention to climate variability from proxy hydrological and atmospheric circulation data with the finest possible temporal resolution and greater chronological control, allowing us to determine the steady centennial- and millennial-scale variability over the Holocene. To do this, we analyze extreme climate changes based on more detailed data, which allow smoothed data used by Mayewski et al. (2004). The aim is also to assess whether archaeological hypotheses postulating climatically controlled changes in human society and civilizations are supported by these data. As natural variability will continue into the future independently of anthropogenic forcing, it increases the need to deepen our understanding of the interplay through time between natural processes and human activities. 
In order to understand the Holocene climate history and the forcing for natural climate variability at decadal to millennial timescales during this period, we compare records of climate variability from proxy hydrological and atmospheric circulation data with ${ }^{14} \mathrm{C}$ content based on studies of tree rings, speleothems, and sediments. On the assumption that the sun and cosmic ray intensity are the major driver of climate changes (van Geel et al. 1999), the ${ }^{14} \mathrm{C}$ content record has been used as a measure of changes in cosmic ray flux and solar activity in the past.

\section{EVIDENCE FOR EXTREME CLIMATIC EVENTS IN THE PAST}

Let us consider some extreme climate changes that can result from solar forcing and have evidence of impacting societies in the past.

\section{The Past Millennium: The Little Ice Age and the Medieval Warm Period}

As high-resolution data about prehistoric climate changes accumulate, historians, archaeologists, and climatologists are looking for connections between climate change and human development. Changes in the Holocene climate may have affected human population as recently as several hundred years ago during the Little Ice Age (Le Roy Ladurie 1967) and during the Medieval Warm Period. Both cold and warm events are known to have had a significant impact on humans. It should be particularly emphasized that solar activity during the Little Ice Age is extremely weak and during the Medieval Warm Period is much higher.

In a recent analysis of an existing temperature reconstruction over the past millennium, Esper et al. (2005) established that there is agreement on major climatic episodes, but substantial divergence in reconstructed temperature amplitudes. Figure 1 demonstrates the arithmetic mean of 5 temperature reconstructions (Esper et al. 2005) compared with a pioneering Northern Hemisphere temperature reconstruction (Mann et al. 1999). Although substantial divergences exist during certain time intervals, the time series display a reasonably coherent picture of major climatic episodes: Medieval Warm Period, Little Ice Age, and Recent Warming. The main problem of all reconstructions is the absolute value of temperature amplitude variation.

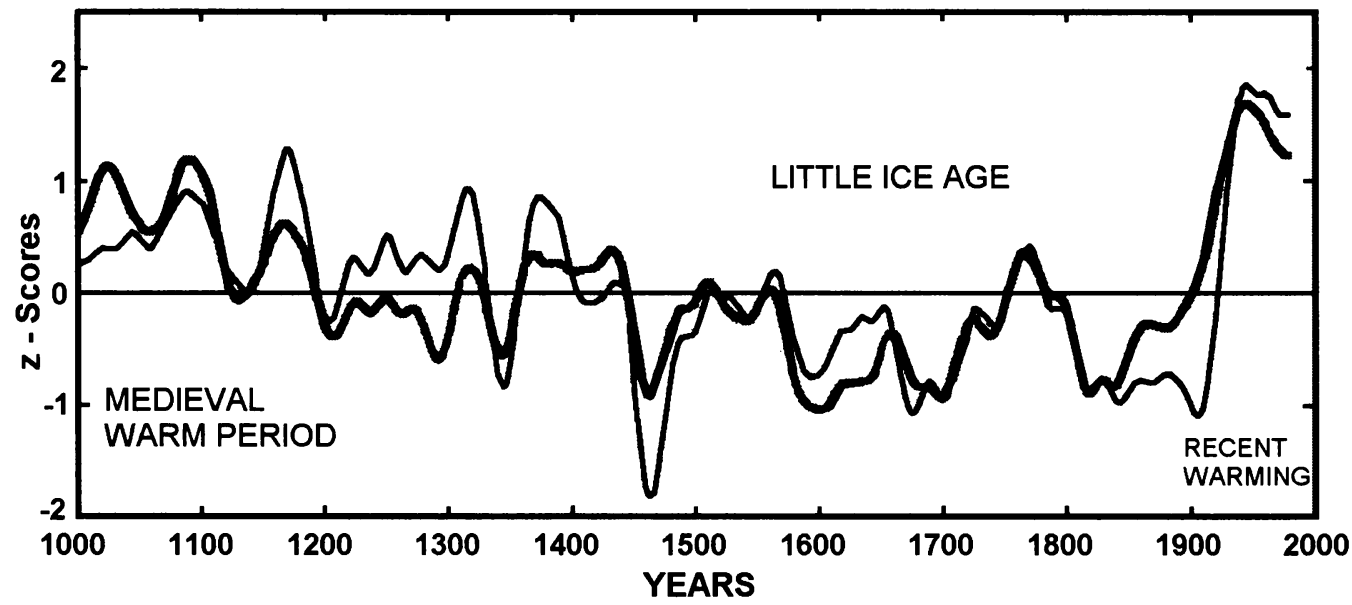

Figure 1 Course of large-scale temperature reconstructions over the common period AD 1000-1979: thick curve = arithmetic mean of 5 reconstructions after smoothing (Esper et al. 2005); thin curve = Northern Hemisphere temperature reconstruction (Mann et al. 1999). 
During the Little Ice Age, extensive areas around Mediterranean Europe and the North Atlanticincluding western and northern Europe, Greenland, and Iceland-experienced unusually cold and wet conditions, as well as many extreme weather events, including floods, landslides, and avalanches (e.g. Le Roy Ladurie 1967; Grove 2002). These dramatic glacial advances often had important practical consequences for nearby human populations. There are widespread reports of famine and disease in Europe during the 17th-19th centuries that are probably related, at least in part, to colder temperatures and altered weather conditions.

As a whole, cooling and glacier advances during the Little Ice Age are widespread at high northern latitudes. For the low altitudes, new high-resolution lacustrine records (Verschuren et al. 2000) show that equatorial east Africa experienced humid conditions. In equatorial Africa, lake levels can be used as an indicator of climate changes. It is interesting to consider past levels in Lake Victoria (Stager et al. 2005) and Lake Naivasha (Verschuren et al. 2000). Lake Victoria, located on the Equator between the 2 main branches of the East African Rift Valley system, is well situated to record large-scale climate events that affected not only tropical Africa but also the polar regions. About $90 \%$ of the lake's water arrives and exits through the atmosphere, making it extremely sensitive to changes in rainfall. The balance of this lake is regulated by evaporation processes as a result of solar variability.

Figure 2 shows the comparison between each of the lakes and the proxy of solar activity- ${ }^{14} \mathrm{C}$ content measured in tree rings. As one can see from this figure, the Victoria and Naivasha basins were unusually arid during Europe's Medieval Warm Period and unusually wet during cool phases of the globally distributed Little Ice Age.

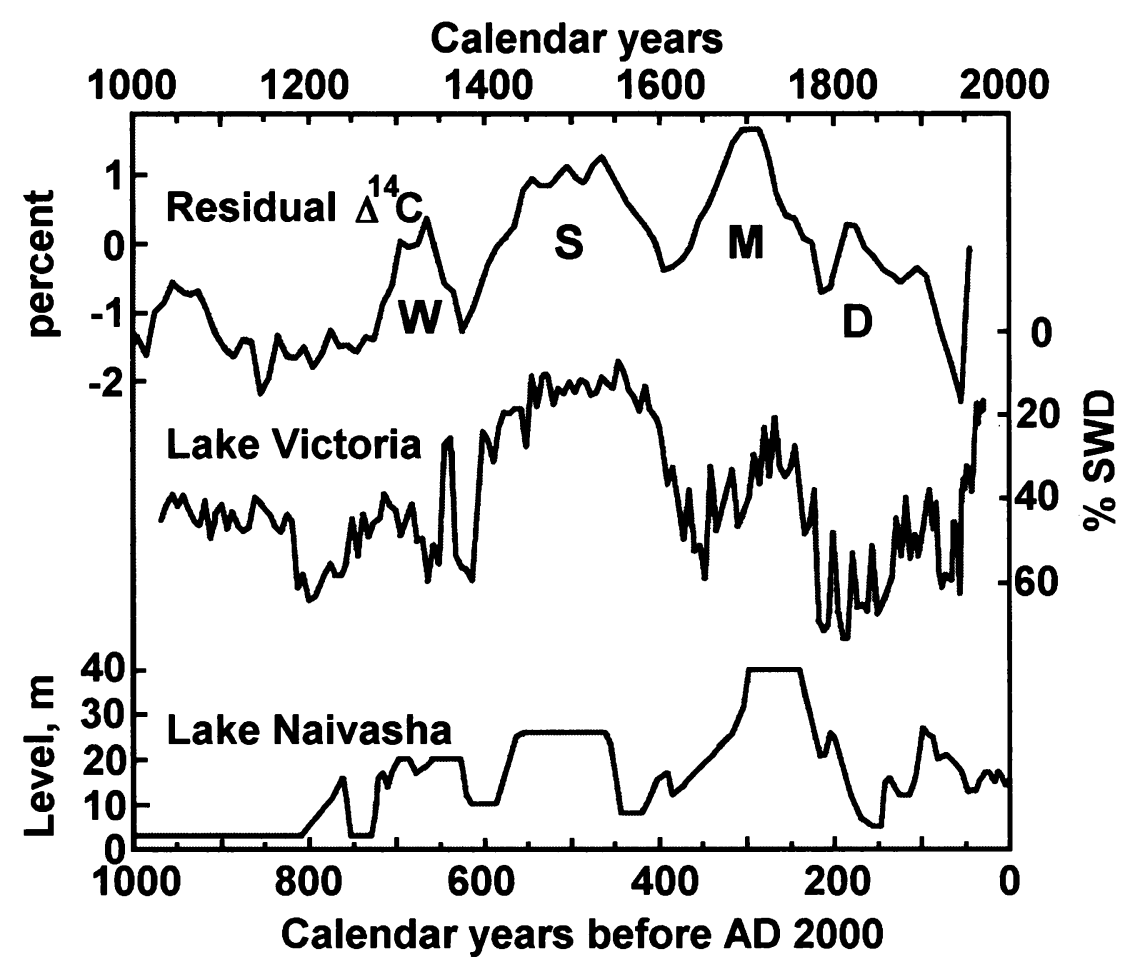

Figure 2 Comparison of proxy records for changes in the hydrology with the proxy for solar activity based on the $\Delta^{14} \mathrm{C}$ record. SWD is the shallow water depth. The minima of solar activity are W Wolf, S - Spörer, M - Maunder, D - Dalton. 
A comparison between atmospheric ${ }^{14} \mathrm{C}$ and hydrological data from tropical Africa demonstrates the relationship between variable solar activity and climate. Maasch et al. (2005) compared 8 welldated, high-resolution records reflecting the range and rate of change of atmospheric circulation and hydrology, obtained at latitudes extending from the Arctic to the Antarctic with the $\Delta^{14} \mathrm{C}$ record over the 2 millennia, and showed that such a relationship is seen on a global scale.

Using gridded drought reconstructions that cover most of the western United States over the past $1200 \mathrm{yr}$, Cook et al. (2004) showed that higher aridity and vast droughts in the time interval AD 900 to 1300 appear broadly consistent with the Medieval Warm Period.

As was demonstrated by Hodell et al. (1995), the decline of the Maya cultures in lowland Guatemala was associated with protracted and severe droughts. New results from Hodell et al. (2005) and Peterson and Haug (2005) confirm the previous conclusion. The general pattern is also consistent with findings from the Cariaco Basin off northern Venezuela (Haug et al. 2003), suggesting that the droughts in the northern Maya lowlands were a widespread phenomenon and not limited to northcentral Yucatan.

\section{Marked Climatic Change at 2500-2800 BP}

Based on historical observations and on climatic proxies such as glacier oscillations and palynology and ${ }^{14} \mathrm{C}$ content, Maise (1998) interpreted as climatically driven the conspicuous decreases of archaeological findings in France, Germany, and Switzerland (e.g. numbers of tombs, settlements, and pottery remains) at around 800 and $400 \mathrm{BC}$. Both proxy climate and archaeological evidence point to a change from a dry and warm to a more humid and cool climate in central and northwestern Europe in this period. As a rule, climatically caused human-population collapses in Europe were more frequent when the level of the ${ }^{14} \mathrm{C}$ content was high, indicating decreased solar activity.

The analysis of both paleo- and archaeomagnetic data and magnetic properties of continental and marine sediments around 2700 BP carried out by Dergachev et al. (2004) has provided extensive evidence for a sharp global cooling around $2700 \mathrm{BP}$. The authors discussed the causes of natural climate variation and proposed that changes of the galactic cosmic ray intensity may play a key role as the causal mechanism of climate change. Since the cosmic ray intensity (reflected by the cosmogenic isotope level in Earth's atmosphere) is modulated by the solar wind and by the terrestrial magnetic field, it may be an important mechanism for long-term solar climate variability.

Available archaeological evidence (van Geel et al. 2004) points to an "empty" Tuva (central-south Siberia) until a sudden immigration and population density increase after $\sim 2800 \mathrm{BP}$. We suppose that a climate shift towards wetter (less dry) climatic conditions was responsible for a suddenly increased carrying capacity (higher biomass production) of the Tuva area. The climate change around $2800 \mathrm{BP}$ was triggered by a temporary decline of solar activity; thus, we hypothesize that the sun was a major factor influencing the cultural blooming and expansion of the Scythian culture.

Based on glacier and lake-level records, Holzhauser et al. (2005) analyzed high-resolution paleohydrological and paleoglaciological data in west-central Europe over the past $3500 \mathrm{yr}$. A data set of tree-ring width, ${ }^{14} \mathrm{C}$ data, and archaeological data, in addition to historical sources, was used to reconstruct fluctuations of the Great Aletsch, the Gorner, and the Lower Grindelwald glaciers in the Swiss Alps. The authors established that glacier fluctuations show strong correspondence with lakelevel variations reconstructed in eastern France (Jura Mountains and Pre-Alps) and on the Swiss Plateau. Thus, this new research supports the hypothesis of climatically driven fluctuations. The results of a comparison between the Great Aletsch glacier and the ${ }^{14} \mathrm{C}$ content confirm the hypothe- 
sis that variations in solar activity were a major forcing factor of climatic oscillations in west-central Europe during this time interval.

\section{Moisture Conditions $5600-5300$ yr Ago}

There is evidence for global climatic change around 5600-5300 yr ago and that this period coincided with the cultural shift at the start of the 3rd millennium BC. Wendland and Bryson (1974) in an extensive analysis pointed out that around $3000 \mathrm{BC}$ there was a sudden climatic shift that coincided with the founding of Dynastic Egypt and the start of the open-circle stone monuments in Britain. Prior to that date, Egypt experienced a much wetter climate than in succeeding years. The authors pointed out that the level of Lake Chad in the Sahara Desert in the millennium before $3000 \mathrm{BC}$ was $30-40 \mathrm{~m}$ higher than its present level, indicating a much higher annual rainfall for the whole area during that time. The climatic change around $3000 \mathrm{BC}$ also was marked in the Alps by an advance of the glaciers (Lamb 1995).

A range of detailed paleoenvironmental analyses carried out by Caseldine et al. (2005) on a series of 3 peat profiles from Achill Island, County Mayo, western Ireland, reveals evidence for an extreme climatic event, probably a storm or series of storms, around 5200-5100 cal BP that caused the deposition of extensive layers of silt on the underlying surfaces of peat. These detailed paleoecological records from Achill Island provide evidence for the impact of climate on human activity in prehistory. The impact a storm or series of storms may have complicated local land use and may have led to the migration of human communities.

Thompson et al. (2006) provided strong evidence for an abrupt tropical climate event $~ 5200 \mathrm{yr}$ ago (the average of $8{ }^{14} \mathrm{C}$ dates) from the analysis of a rooted, soft-bodied plant deposit discovered after it was exposed along the west-central margin of the rapidly retreating Quelccaya ice cap (Peru). This abrupt event marked the transition from temperate to cooler conditions and was widespread and spatially coherent though much of the tropics and was coincident with structural changes in several civilizations.

Recently, the history of variations in water level of Lake Constance near the archaeological site of Arbon-Bleiche 3 (Switzerland) was reconstructed by Magny et al. (2006) from sediment and pollen analyses of a sediment sequence. The authors established an abrupt rise in lake level in the vicinity of $5375 \mathrm{cal} \mathrm{BP}$. They show that this event was the last of a series of 3 episodes of successively higher lake levels, the first occurring at 5600-5500 cal BP (Figure 3). The 3 successive episodes of higher lake levels between 5600 and $5300 \mathrm{cal} \mathrm{BP}$ at Arbon-Bleiche 3 coincided with climatic cooling and/ or changes in moisture conditions in various regions of both hemispheres. As the high lake level was synchronous with an abrupt increase in the amplitude of ${ }^{14} \mathrm{C}$ content in this period, this supports the hypothesis of an abrupt climate change forced by varying solar activity. The authors found similarities between lake-level records from Lake Constance and from Jura Mountains lakes and noted that, despite different seasonal hydrological regimes of these lakes, their similarities can serve as a crucial factor in considering the possible impact of climate change on environments.

Moreover, as noted by the authors, the chronology of events 3,5, and 7 in Arbon-Bleiche 3 is fully in agreement with that of the regional phase of higher lake levels over 5650-5200 cal BP from the Jura Mountains, the northern French Pre-Alps, and the Swiss Plateau. It should be mentioned that according to Kutschera and Müller (2003), ${ }^{14} \mathrm{C}$ dates indicate that the burial of the Alpine Iceman occurred at 5300-5160 cal BP, very close to the abrupt climate change recorded by a sudden rise in lake level in Arbon-Bleiche 3. 


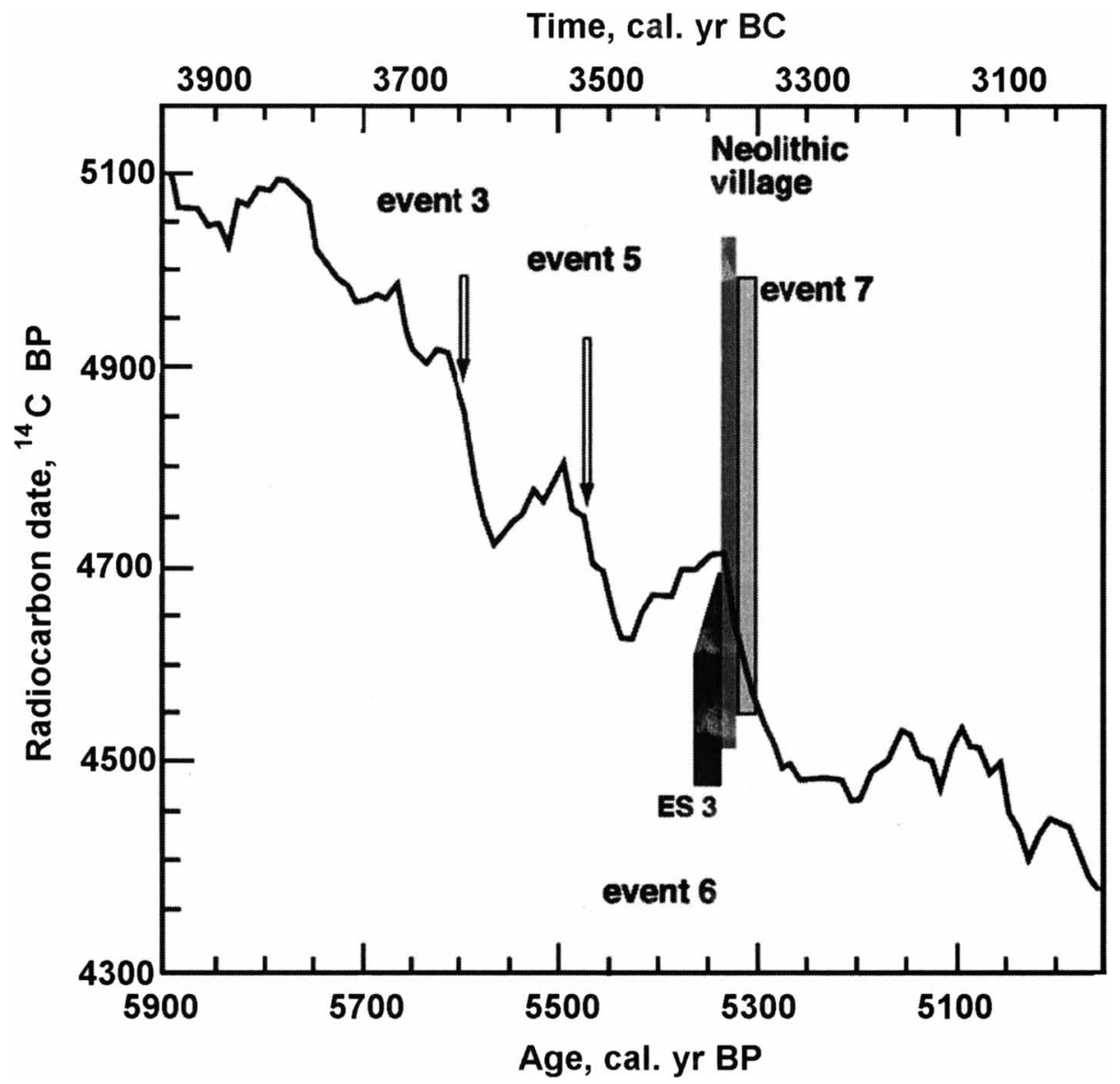

Figure 3 Correlation between the Arbon-Bleiche 3 lake-level variations (Magny et al. 2006) and the calibration ${ }^{14} \mathrm{C}$ curve of Stuiver et al. (1998). Events 3, 5, 6, and 7 refer to lake-level episodes; ES = erosion surface.

\section{The 8200-BP Cooling Event}

The most significant change, which is recorded in Greenland ice cores, occurred between 8400 and $8000 \mathrm{cal}$ BP and is known as the "8200-yr cold event" (Alley et al. 1997). It is widely believed that a cold event occurring around $8200 \mathrm{cal}$ BP was the strongest Holocene cooling episode, with clear expressions in Greenland, the North Atlantic, Europe, North America, north Africa, and the Venezuelan Cariaco Basin (see e.g. Baldini et al. [2002] and references in this paper). The proposed cause for this event is the catastrophic drainage of the large proglacial Laurentide lakes Agassiz and Ojibway into the Hudson Strait, including a very brief warming episode within the event (Renssen et al. 2001; Ellison et al. 2006). In response to increasing freshwater inputs associated with the decay of the Laurentide ice sheet, the North Atlantic thermohaline circulation (THC) could have weakened and heat transport to the North Atlantic region could have decreased.

In the review article of Rohling and Pälike (2005), new well-dated, highly resolved climate proxy records in the vicinity of the 8200 -BP event were considered. The inferred cause for this event, the broader climate context, and the global distribution of the event were evaluated. They pointed out that climate variability in this time follows the basic pattern of the long-term periodicity during the 
Holocene, and the manifestation of climate cooling is similar to the Little Ice Age. Rohling and Pälike (2005) suggested that the possible cause of this event was a fluctuation in the solar output.

By way of illustration, let us consider high-resolution records of ${ }^{18} \mathrm{O}$ in speleothems. Neff et al. (2001) presented a high-resolution study of variation in the Indian Ocean monsoon during the period from 9600 to $6100 \mathrm{BP}$, derived from oxygen isotope variation in a $\mathrm{Th} / \mathrm{U}$-dated speleothem from Oman. The speleothem $\delta^{18} \mathrm{O}$ values serve as a proxy for estimating variation in monsoon intensity by measuring past changes in $\delta^{18} \mathrm{O}$ of monsoon rainfall as recorded in speleothem calcite $\delta^{18} \mathrm{O}$. (Time variations in ${ }^{18} \mathrm{O}$ content in stalagmites reflect changes in the amount of monsoon precipitation.) The speleothem studied is taken from Hoti Cave, located in northern Oman on the southwestern side of the Oman Mountains $\left(57^{\circ} 21^{\prime} \mathrm{E}, 23^{\circ} 05^{\prime} \mathrm{N} ; 800 \mathrm{~m}\right.$ asl).

In Figure 4, the content of $\delta^{18} \mathrm{O}$ in calcium carbonate measured for the time interval from 9600 to $6200 \mathrm{yr}$ ago is compared with the changes in the ${ }^{14} \mathrm{C}$ content in tree rings (Stuiver et al. 1998), reflecting solar activity variations. For the fastest growth interval, between 7900 and $8300 \mathrm{BP}$, the resolution was very high, up to $1.4 \mathrm{yr}$ between samples. The $\delta^{18} \mathrm{O}$ values vary between -4 and $-6 \%$ o VPDB, reflecting the characteristically low $\delta^{18} \mathrm{O}$ of monsoonal rainfall (Figure 4). Modern stalagmites in this cave also have comparatively positive $\delta^{18} \mathrm{O}$ ranging from 0 to $-2 \%$, corresponding to the present arid climate (Burns et al. 1998).

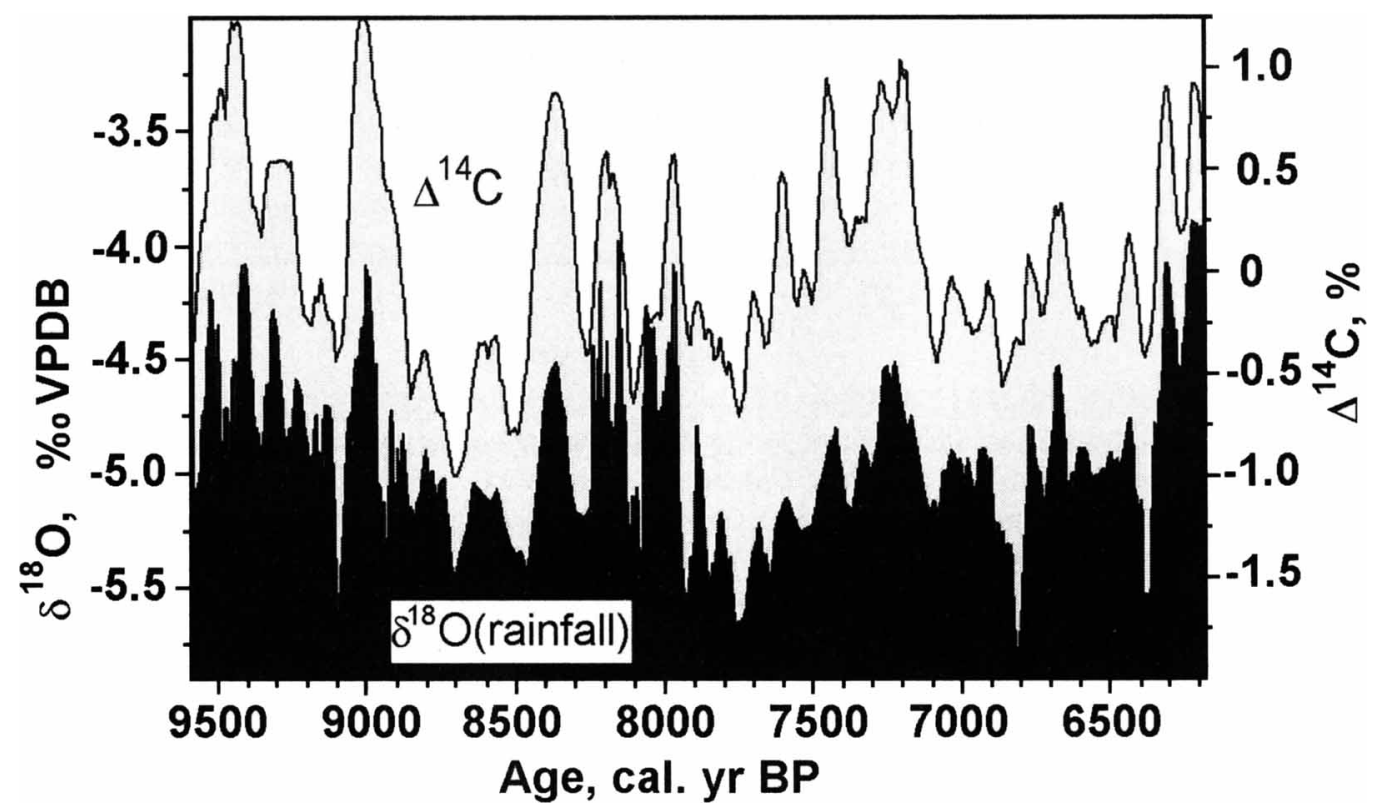

Figure $4 \mathrm{~A}$ direct comparison of record in speleothem calcite $\delta^{18} \mathrm{O}$ (Neff et al. 2001) with atmospheric $\Delta^{14} \mathrm{C}$ from tree rings (Stuiver et al. 1998).

From this comparison of both curves, we can see that the overall character, shape, and amplitude of individual peaks are strikingly similar. Even fine details of a change in $\delta^{18} \mathrm{O}$ are in good agreement with $\Delta^{14} \mathrm{C}$ changes. In the time span from 8500 to $8000 \mathrm{cal} \mathrm{BP}$, there are strong peaks at 8400,8200 , and $8000 \mathrm{cal} \mathrm{BP}$, with the 200 -yr periodicity both in $\delta^{18} \mathrm{O}$ data and $\Delta^{14} \mathrm{C}$ data similar to the pattern of climate and solar activity change during the Little Ice Age in the past millennium. This implies that much of the climate variation at these timescales can be attributed to solar forcing through variations in solar activity and intensity of galactic cosmic ray intensity. As to the magnitude of abrupt 
climate change of the 8200 -BP event in the tropics, this result implies that the primary forcing on the monsoon over this time period is solar activity.

Fleitmann et al. (2003) used a $\delta^{18} \mathrm{O}$ monsoon record from a stalagmite of Qunf Cave in southern Oman $\left(17^{\circ} 10^{\prime} \mathrm{N}, 54^{\circ} 18^{\prime} \mathrm{E} ; 650 \mathrm{~m}\right.$ asl; covering the period $\left.10,300-8000 \mathrm{BP}\right)$ to show that decadal to centennial variations in monsoon precipitation are in phase with temperature fluctuations recorded in Greenland ice cores. Taking into account both the stalagmite and GRIP records, decadal-scale intervals of reduced monsoon precipitation (more positive $\delta^{18} \mathrm{O}$ values) correlate with cooling events in Greenland and vice versa, as best expressed at 9100 and 8200 BP.

\section{REGULARITY OF ABRUPT CLIMATE FLUCTUATIONS AT MILLENNIAL TIMESCALE DURING THE HOLOCENE}

Both very cold and very warm climate changes are known to have had a significant impact on human populations. Although considerable effort has been given to the study of temperature change in climate records, determining the range and rate of change of atmospheric circulation and hydrology is a challenging task. At present, there are possibilities to identify key records from many parts of the world and to use a vast range of archives from ice cores, lake levels, and corals in order to obtain the information about global or local climate changes not only in terms of temperature but also in terms of hydrology. This has had a larger impact on people than temperature variability has in the most densely populated parts of the world.

During the Holocene, large fluctuations in hydrology and atmospheric circulation, as revealed by a number of archives and proxies, took place on the continents with distinct amplitudes both in the Northern Hemisphere and in the tropics and subtropics. The main attention in continental paleohydrology is devoted to the analysis of information from groundwater, mountain glaciers and permafrost, lake, wetland, soil, and river systems.

Lake basins offer highly sensitive archives because lake-level records can document past changes in the water budget in relation to climatic changes. Lake levels are influenced by climatic parameters affecting both evaporation and precipitation. To reconstruct a Holocene mid-European lake-level record, Magny (2004) used a data set of $180{ }^{14} \mathrm{C}$, tree-ring, and archaeological dates obtained from sediment sequences of 26 lakes in the Jura Mountains, the northern French Pre-Alps, and the Swiss Plateau. The dates were separated into 2 groups: lower and higher lake-level episodes. The phases of high lake levels are characterized by a deposition of more mineralized sediments, whereas the phases of low lake levels are characterized by an extension of peat or organic detritus accumulation, allowing ${ }^{14} \mathrm{C}$ dating in the nearshore areas. According to a quantitative reconstruction of climate variables, phases of higher lake levels coincide with an increase in annual precipitation, a decrease in summer temperature, and a shortening of the growing season. Figure 5 shows that the dates form clusters, suggesting an alternation higher lake-level phases that point to a rather cold Holocene climate. There is clearly a 2000 -yr quasi-periodicity in cold climate change. Thus, the mid-European lake-level record testifies to a significant instability of the Holocene climate.

The Holocene wetting of the northern desert belt of Africa was studied by Gasse (2005). She suggested that from about 11,000 to $5000 \mathrm{BP}$, the Sahara had a green landscape with lakes and rivers, supporting large mammals and prosperous Neolithic societies. Lake, pollen, and speleothem records registered weakening of the summer Indian and African monsoons and dry spans interrupted the Holocene wet period (Figure 6). As can be seen from Figure 6, major Holocene droughts are repeated every $2000-2500 \mathrm{yr}$. 


\section{Age, cal. kyr BP}

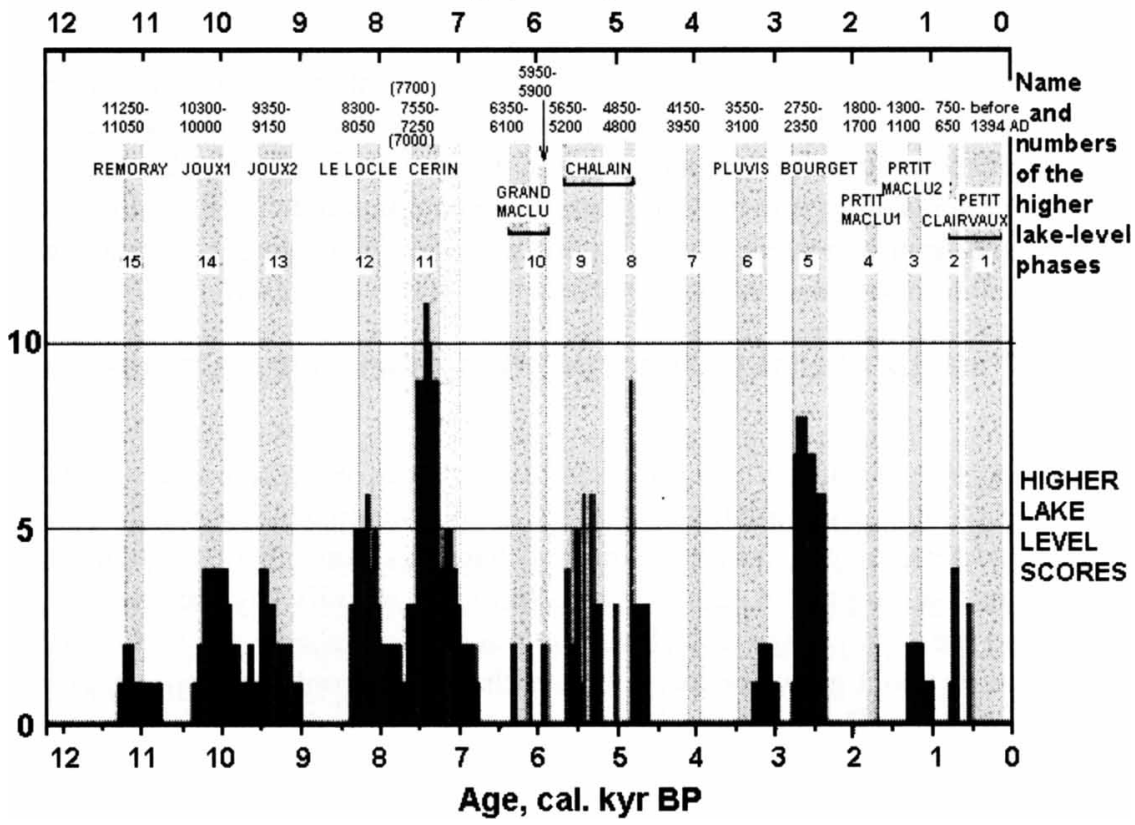

Figure 5 Distribution of the dates of higher lake-level events reconstructed in the Jura Mountains, the northern French Pre-Alps, and the Swiss Plateau over the Holocene period (Magny 2004). The vertical scales represent the number of dates for successive 50 -yr intervals between 12,250 and 0 cal BP.

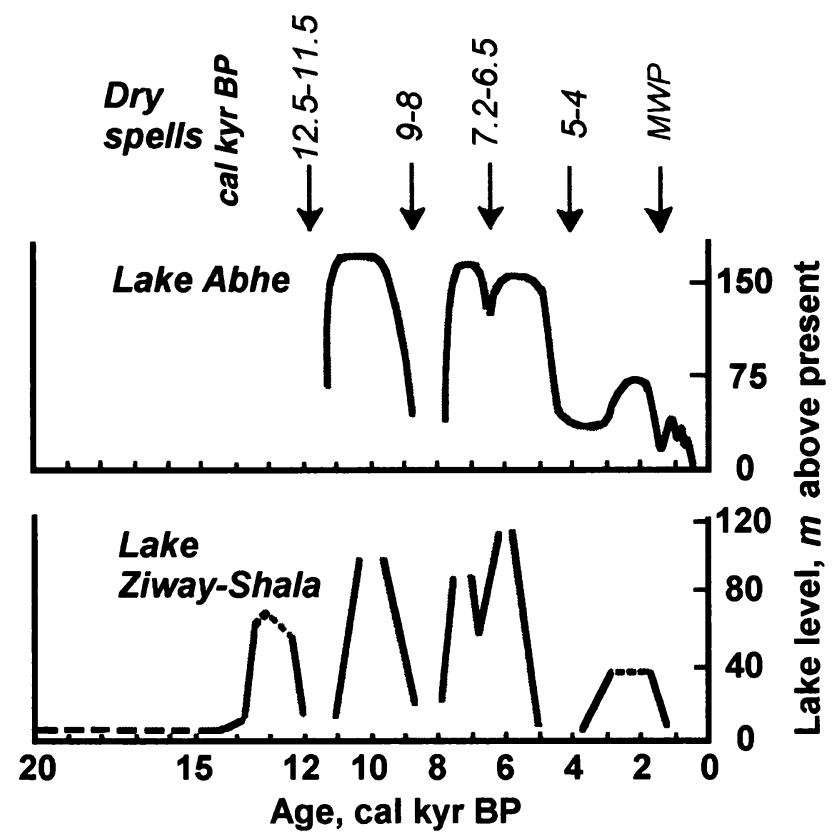

Figure 6 A comparison of lake-level fluctuations in the Ziway-Shala Lake in the Sahara-Sahel (Hoelzmann et al. 1998) and the Ethiopian Abhe Lake (Gasse 2000) reflected Indian and African monsoons, with dry spells due to major Holocene droughts (Gasse 2005). 
A storm chronology was inferred by Noren et al. (2002) from terrigenous sedimentation inwash layers, which reflect rainfall events of exceptional intensity/duration in the 13 lake drainage basins in the NE United States (Figure 7). The frequency of storm-related floods in the NE United States has varied in regular cycles during the past $13,000 \mathrm{yr}$ with a characteristic millennial periodicity. This pattern is consistent with long-term changes in the average sign of the Arctic Oscillation. As was shown by Mayewski et al. (2004), atmospheric circulation modes controlled by sea-level pressure patterns - e.g. the El Niño-Southern Oscillation (ENSO), the North Atlantic Oscillation (NAO), and the Arctic Oscillation (AO) - accounting for significant fractions of climatic variability on short timescales are modulated on longer timescales. Figure 7 shows that maxima of terrigenous influx coincide with high storminess and flooding episodes in other records from the North Atlantic area, and with cool periods in Greenland and Europe as recorded in glaciers (Hormes et al. 2001).

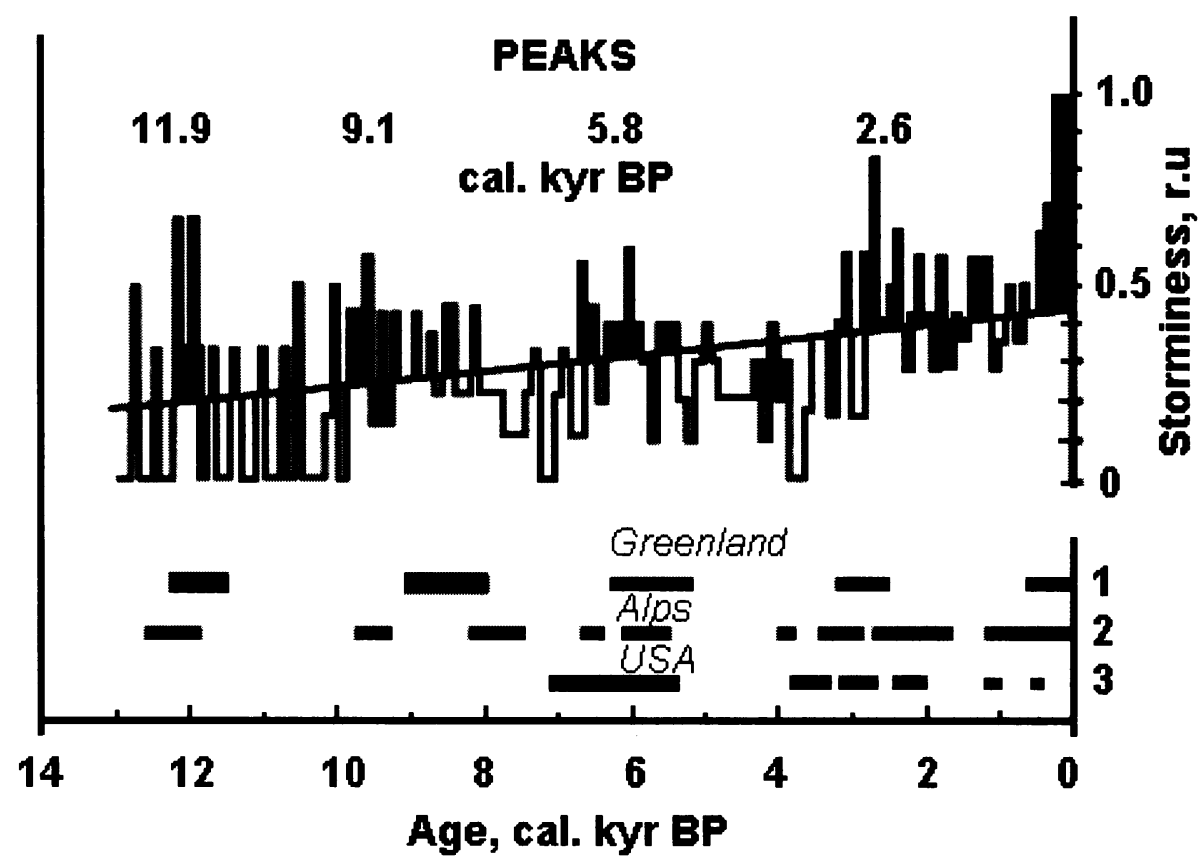

Figure 7 Comparison of millennial-scale variability storminess (Noren et al. 2002) in the NE United States with other relevant climatic records: 1 - Greenland ice-core glaciochemical cold events (Mayewski et al. 2004); 2 - glacial expansions in the Alps (Hormes et al. 2001); and 3 - periods of increased magnitude of the largest floods in the north-central United States (Knox 1999).

On the basis of the results of palynological research on 2 cores from the Song Hong (Red River) delta in the subtropical zone of Asia, centennial- to millennial-scale climate changes and their impacts on humans during the Holocene were proposed by Li et al. (2006). Three cycles of cooling and warming were identified during the last $5000 \mathrm{yr}$ : a cool and wet climate during 4530-3340 cal BP, 2100-1540 cal BP, and 620-130 cal BP; a warm and dry climate during 3340-2100 cal BP and 1540-620 cal BP; and the present warm climate. The first and last cooling events correspond to global Holocene cooling events, the Neoglacial period and the Little Ice Age, respectively. Each persisted for 500-1000 yr, and they occurred at intervals of 1500-2000 yr. 


\section{DISCUSSION}

As indicated earlier, the Holocene (the last 11,500 yr) is characterized by significant climate change. Alpine glaciers are sensitive climatic indicators. The periods of cold and humid climatic conditions stimulate the growth of glaciers (Denton and Karlén 1973) with 2400-yr periodicity beginning at the Little Ice Age 200-300 yr ago and changes in the content of sea salt and dust deposition in ice cores from central Greenland (O'Brien et al. 1995). Severe climatic conditions are fixed by O'Brien et al. (1995) in the following time intervals: $0-700,2400-3100,5000-6100,7800-8800$, and more than $11,300 \mathrm{yr}$ ago.

Using various paleoclimatic records of high resolution and reliable methods of dating, studies are now underway on climatic variability in the Holocene not only in such archives as tree-rings and layers of polar ice but also varves, corals, stalagmites, etc. Lake basins are also highly sensitive archives because the record of lake-level changes is indicative of a change of the water budget due to climatic oscillations leading to precipitation or evaporation.

A pattern of major changes in high-resolution climate proxy records, derived by Mayewski et al. (2004), demonstrates their worldwide significance. Most of the climate change events in 50 globally distributed records during the Holocene are characterized by polar cooling, tropical aridity, and major atmospheric circulation changes; although in the most recent cold interval (600-150 cal BP), polar cooling was accompanied by increased moisture in some parts of the tropics. Several intervals coincide with major disruptions of civilization, suggesting that such disruptions would be related to climate variability. From these high-resolution climate proxy records from the North Pole to South Pole, there seems to be a strong relationship between solar variability and changes in hydrology and atmospheric circulation over the last $10,000 \mathrm{yr}$.

Figure 8 presents a comparison of lake-level record changes from 26 lakes in the Jura Mountains (see Figure 5), the northern French Pre-Alps, and the Swiss Plateau (Magny 2004) with the record of the Polar Circulation Index (PCI) (Mayewski et al. 1997) from glaciochemical data in GISP2 ice cores. The PCI is a relative measure of the average size and intensity of polar atmospheric circulation, which increases during colder periods. There is near correlation between the major changes in the mid-European lake level, in the intensity of polar atmospheric circulation from the GISP2 record, and in the atmospheric ${ }^{14} \mathrm{C}$ residual content (Figure 8) based on tree-ring records (Stuiver et al. 1998), which may be considered a proxy record for past changes in solar activity. The long period of $\sim 2400 \mathrm{yr}$ is the characteristic property of major changes in Figure 8. Vasiliev and Dergachev (2002), using spectral and bispectral analysis of ${ }^{14} \mathrm{C}$ content from tree rings, showed that this long period of $\sim 2400 \mathrm{yr}$ is the period of main modulation of the ${ }^{14} \mathrm{C}$ time series, suggesting that solar forcing is mainly responsible for such changes.

Thus, the data outlined in Figure 8 demonstrate that at least the large-scale cold events fixed in various paleoclimatic archives from the Northern Hemisphere show close correlation in time. The close correlation between proxy data and the variations in atmospheric ${ }^{14} \mathrm{C}$ content presented in Figure 8 suggests that the key factor in Holocene climate variability over the North Atlantic area is changes in the solar activity. Climate changes due to variations in solar activity can have significant changes in the type of settlement and culture of Neolithic and more yearly historic groups in the subalpine region.

Although the causes for these global changes in proxy climate records are not fully understood, they may be caused by changes in solar activity, including the energy output of the sun, and changes in the internal variability of the ocean-atmosphere system. Simulations of time-dependent climate 


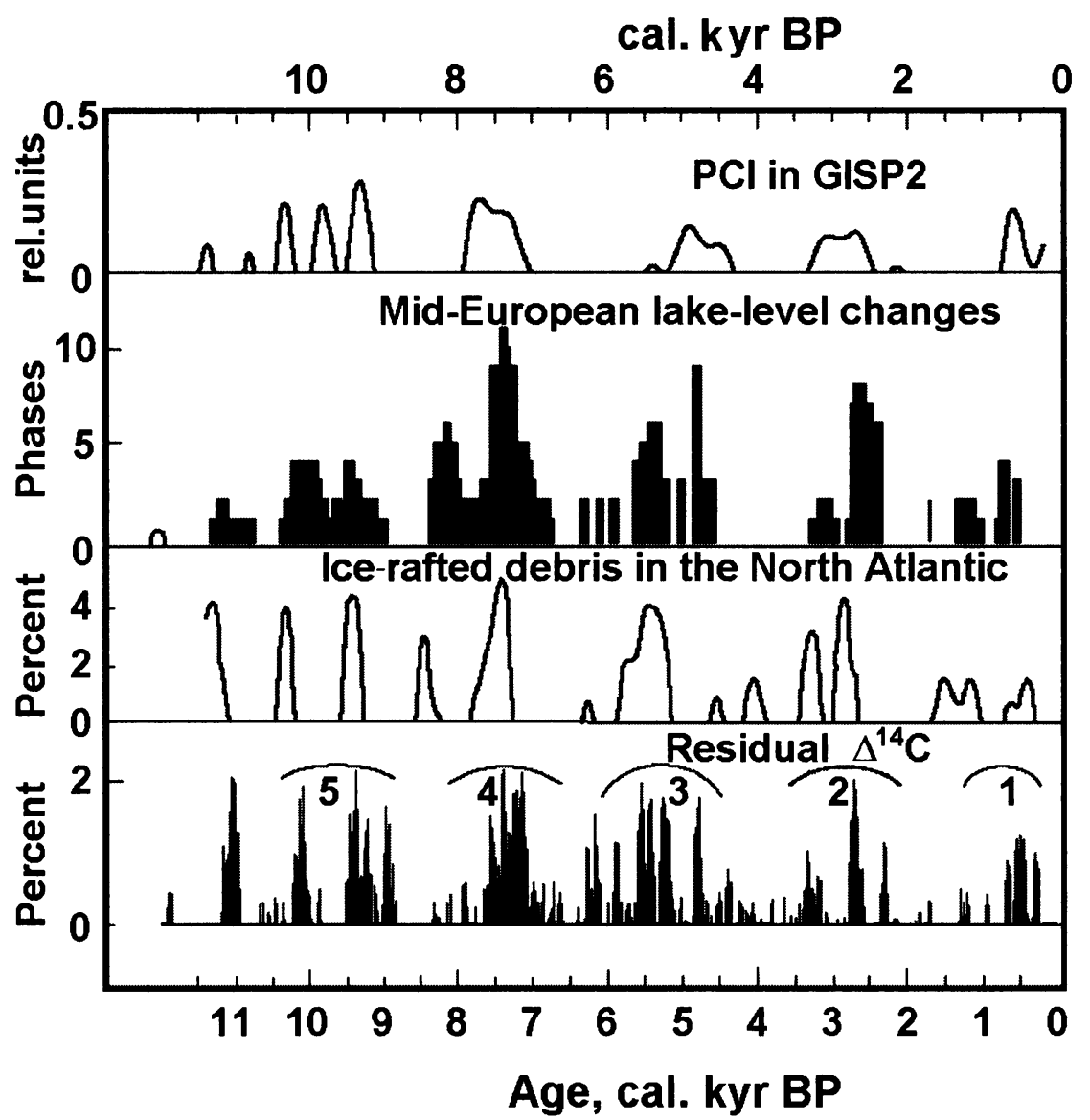

Figure 8 Comparison of the Polar Circulation Index (PCI) from GISP2 (Mayewski et al. 1997) with the mid-European lake-level fluctuations (Magny 2004), with the ice-rafting debris events in the North Atlantic Ocean (Bond et al. 2001), and with the atmospheric residual ${ }^{14} \mathrm{C}$ content (Stuiver et al. 1998) during of the Holocene.

response to solar radiative forcing for the last 500-1000 yr indicate that solar forcing indeed dominates over internal variability in generating temperature variations at decadal and longer timescales and large spatial scales (e.g. Rind et al. 1999; Amman 2005).

Exact measurements of ${ }^{14} \mathrm{C}$ content in annual tree rings allow us to trace continuous long-term changes in level of solar activity during more than the last $10 \mathrm{kyr}$ (Stuiver et al. 1998). An independent check of such representations of solar activity change comes from the analysis of ${ }^{10} \mathrm{Be}$ levels in ice cores from Greenland (Finkel and Nishizumi 1997), where it is shown that the temporal variation of both cosmogenic isotopes is similar. As changes of levels ${ }^{14} \mathrm{C}$ and ${ }^{10} \mathrm{Be}$ are subject to various perturbations in exchange reservoirs, these common features allow us to draw the conclusion that the probable reason of these features is the sun. As follows from direct measurements of solar irradiance during more than $25 \mathrm{yr}$ (Fröhlich 2000), solar irradiance changes are in phase with solar sunspots. This allows us to reconstruct both solar activity and solar irradiance from cosmogenic isotopes.

The reconstruction of solar irradiance from the change of ${ }^{14} \mathrm{C}$ content covering $10 \mathrm{kyr}$ is shown in Figure 9 (Weber et al. 2004). The lowest levels of solar irradiance and the highest levels of ${ }^{14} \mathrm{C}$ con- 
tent are repeated through $\sim 2400$ yr. These episodes are shown in Figure 9 by arrows. Numerous studies have found evidence of solar irradiance forcing in proxy data. Consideration of the solar forcing of climate variability (Figure 9b) testifies that the lowest solar irradiance levels fall on the coldest intervals, which are similar to the Little Ice Age. The Greenland ice contains sea salt and dust depositions that indicate large-scale changes with a quasi $2500-y r$ cycle (O'Brien et al. 1995), consistent with worldwide glacial expansions (Figure 9b).

\section{CONCLUSION}

An analysis of different climatic parameters and solar variability shows that the response in atmospheric parameters to the irradiance forcing can be characterized as the direct response of the climatic system. Many proxy records reflect a combined temperature and precipitation signal. Temperature variations reflect the primary response of the climate system. A stronger response shows surface air temperature, monsoon precipitation, and glacier length. A direct response of these parameters is attenuated at shorter timescales by the thermal inertia of the oceans. As to the oceanic response, it is strongly modified by internal feedback processes. Temperature and precipitation variations correlate increasingly well with the applied forcing for longer timescales and larger spatial scales. A positive correlation between solar activity (solar irradiance) and the summer monsoon over North Africa (Figure 4) was established by Neff et al. (2001) and over India by Gupta et al. (2003). At the same time, equatorial east Africa was relatively dry during periods (Figure 2) of high solar activity (solar irradiance) (Verschuren et al. 2000).

The mechanism for the connection between solar variability and atmospheric circulation may be due to solar ultraviolet radiation or cosmic ray flux modulated by solar activity. Changes in ultraviolet radiation from the sun may lead to a change in ozone production in the lower stratosphere accompanied by the change in tropospheric dynamics, whereas cosmic ray flux changes may directly lead to a change in global cloud cover, as demonstrated by the correlation between the variation in cosmic ray flux and the observed global cloud cover. An increase in the low cloud cover due to cosmic ray flux may lead to wetter, cooler conditions at different latitudes (Svensmark et al. 2007).

Thus, the analysis of the numerous varieties of proxy climatic records is indicative of the high variability of the Holocene climate. Furthermore, paleoclimate records reveal the presence of fairly regular patterns of major global climate changes. A correlation of historical records of solar activity and climate change and also cosmogenic isotopes, proxies for solar activity, and millennial-scale variability in paleoclimate records demonstrates the connection between solar variability and climate change. As mentioned above, cosmogenic isotope records can be used as a measure of changes in solar activity and in cosmic ray flux in the past. More significant changes in the Holocene climate are characterized by a quasi 2400 -yr periodicity in cold conditions possibly caused by changes in solar activity. The sun-climate relationship is most clearly seen during the Little Ice Age. Sharp climate change events appear to have been sufficiently large to affect humans and ecosystems. Major disruptions in civilizations coincided with changes in hydrology and polar cooling. The collapse of the Mayan civilization and Akkadian Empire coincided with major abrupt droughts (Ristvet 2003), whereas the collapse of Greenland colonies coincided with a period of polar cooling. Additional study is needed to investigate the rate and change of atmospheric circulation in the past. The change in the processes of atmospheric circulation may alter the distribution of precipitation both high and low latitudes that may lead to the large fluctuations in lake levels, monsoon activity, and redistribution of moisture and heat on Earth's surface.

As a whole, it is necessary to study past cultural adaptations to persistent climate change to gain a valuable perspective into possible responses of modern societies to future climate change. 

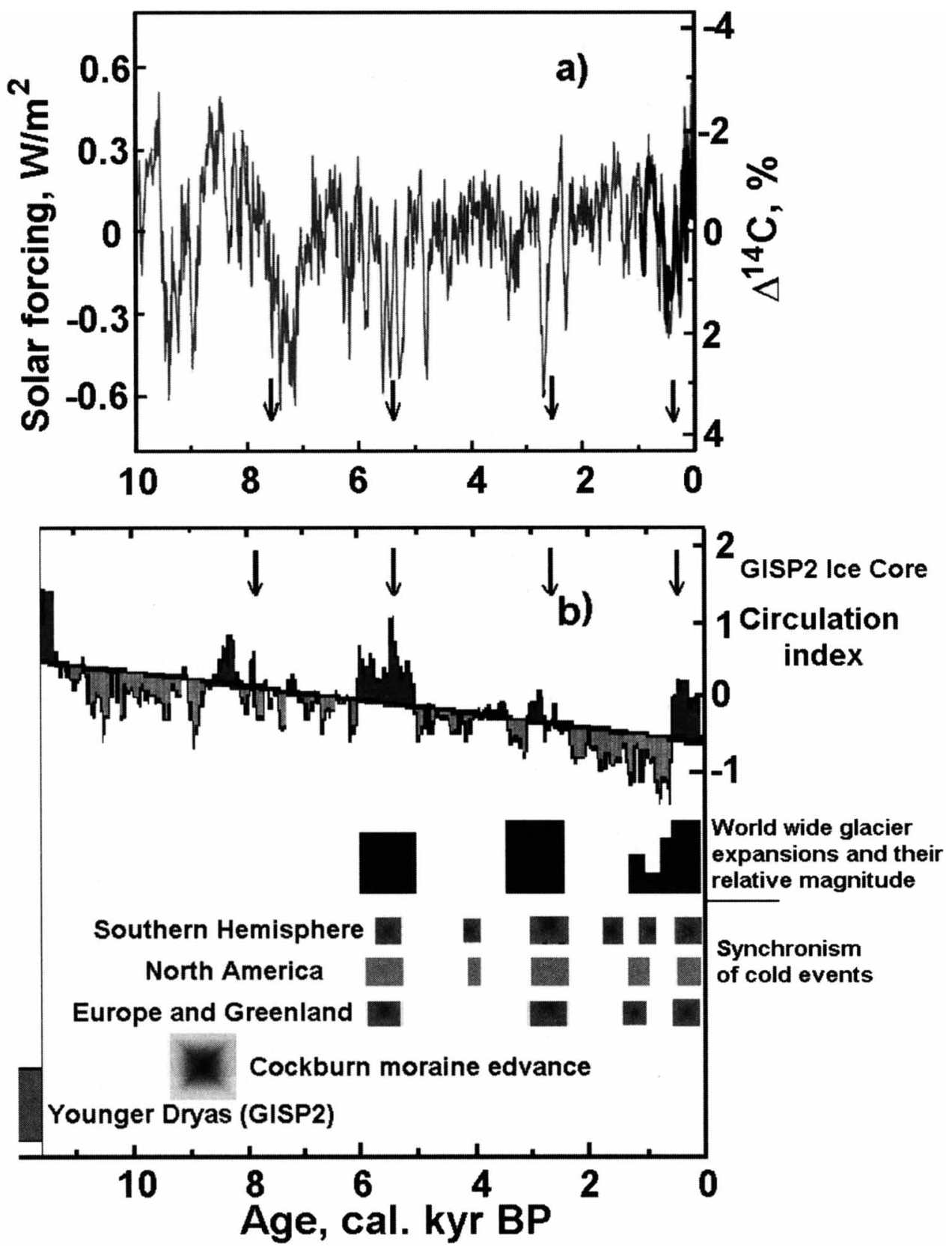

Figure 9 The reconstruction of Weber et al. (2004) solar irradiance forcing (gray line) based on the residual ${ }^{14} \mathrm{C}$ content (Stuiver et al. 1998) for the last 10,000 yr (left axis; in watts per square meter $\left[\mathrm{W} / \mathrm{m}^{2}\right]$ ). The right axis gives the residual ${ }^{14} \mathrm{C}$ record. The black line shows the Lean et al. (1995) reconstruction of historic irradiance variations is extended back in time to AD 1000 by the independent ${ }^{10} \mathrm{Be}$ record (Bard et al. 1997) large-scale climate changes obtained on a basis of the record of the Polar Circulation Index from glaciochemical data in GISP2 ice cores (Mayewski et al. 1997) and episodes of distinct glacier advances: European, North American, and Southern Hemisphere (Denton and Karlén 1973), and central Asia (Haug et al. 2001). The most low solar irradiance levels fall in the coldest intervals. 


\section{ACKNOWLEDGMENTS}

This work was supported by the INTAS (projects 03-51-44450, Russian Foundation for Basic Research, projects 06-02-16268, 06-04-48792, 06-05-64200), Presidium of Russian Academy of Sciences (RAS) (program "Environmental and Climatic Changes" and program "Adaptation of the Population and Cultures to Environmental Change and Social and Man-caused Transformations"), and Presidium of the St. Petersburg Scientific Centre of RAS (Regional Programs).

\section{REFERENCES}

Alley RB, Mayewski PA, Sowers T, Stuiver M, Taylor KC, Clark PU. 1997. Holocene climatic instability: a prominent, widespread event 8200 yr ago. Geology 25(6):483-6.

Amman CM. 2005. Solar signal in records and simulations of past climates. Memorie della Societa Astronomica Italiana 76(4):802-4.

Baldini JUL, McDermott F, Fairchild IJ. 2002. Structure of the 8200 -year cold event revealed by a speleothem trace element record. Science 296(5576):2203-6.

Bond G, Kromer B, Beer J, Muscheler R, Evans MN, Showers W, Hoffmann S, Lotti-Bond R, Hajdas I, Bonani G. 2001. Persistent solar influence on North Atlantic climate during the Holocene. Science 294(5549):2130-6.

Burns SJ, Matter A, Frank N, Mangini A. 1998. Speleothem-based paleoclimate record from northern Oman. Geology 26(6):499-502.

Caseldine C, Thompson G, Langdon C, Hendon D. 2005. Evidence for an extreme climatic event on Achill Island, Co. Mayo, Ireland around 5200-5100 cal yr BP. Journal of Quaternary Science 20(2): 169-78.

Cook ER, Woodhouse CA, Eakin CM, Meko DM, Stahle DW. 2004. Long-term aridity changes in the western United States. Science 306(5698):1015-8.

Denton GH, Karlén W. 1973. Holocene climatic variations-their pattern and possible cause. Quaternary Research 3(2):155-74.

Dergachev VA, Raspopov OM, van Geel B, Zaitseva GI. 2004. The 'Sterno-Etrussia' geomagnetic excursion around $2700 \mathrm{BP}$ and changes of solar activity, cosmic ray intensity, and climate. Radiocarbon 46(2):661-81.

Eddy JA. 1976. The Maunder minimum. Science 192(4245):1189-202.

Ellison CRW, Chapman MR, Hall IR. 2006. Surface and deep ocean interactions during the cold climate event 8200 years ago. Science 312(5782):1929-32.

Esper J, Wilson RJS, Frank DC, Moberg A, Wanner H, Luterbacher J. 2005. Climate: past ranges and future changes. Quaternary Science Reviews 24(20-21): 2164-6.

Finkel RC, Nishizumi K. 1997. Berillium-10 contents in the Greenland Ice Sheet Project 2 ice core from 3-40 ka. Journal of Geophysical Research 102(C12): 26,699-706.

Fleitmann D, Burns SJ, Mudelsee M, Neff U, Kramers J, Mangini A, Matter A. 2003. Holocene forcing of the
Indian monsoon recorded in a stalagmite from southern Oman. Science 300(5626): 1737-9.

Friis-Christensen E, Lassen K. 1991. Length of the solar cycle: an indicator of solar activity closely associated with climate. Science 254(5032):698-700.

Fröhlich C. 2000. Observations of irradiance variations. Space Science Reviews 94(1-2):15-24.

Gasse F. 2000. Hydrological changes in the African tropics since the Last Glacial Maximum. Quaternary Science Reviews 19(1-5):189-211.

Gasse F. 2005. Continental palaeohydrology and palaeoclimate during the Holocene. Comptes Rendus Geoscience 337(1-2):79-86.

Grove JM. 2002. Climatic change in northern Europe over the last two thousand years and its possible influence on human activity. In: Wefer G, Berger W, Behre $\mathrm{K}-\mathrm{E}$, Jansen E, editors. Climate Development and History of the North Atlantic Realm. Berlin: SpringerVerlag. p 313-26.

Gupta AK, Anderson DM, Overpeck JT. 2003. Abrupt changes in the Asian southwest monsoon during the Holocene and their links to the North Atlantic Ocean. Nature 421(6921):354-7.

Harrison RG, Stephenson DB. 2005. Empirical evidence for a nonlinear effect of galactic cosmic rays on clouds. Proceedings of the Royal Society of London A 462(2068):1221-33.

Haug GH, Hughen KA, Sigman DM, Peterson LC, Röhl U. 2001. Southward migration of the Intertropical Convergence Zone through the Holocene. Science 293(5533):1304-8.

Haug GH, Günther D, Peterson LC, Sigman DM, Hughen KA, Aeschlimann B. 2003. Climate and the collapse of Maya civilization. Science 299(5613):17315.

Hodell DA, Curtis JH, Brenner M. 1995. Possible role of climate in the collapse of Classic Maya civilization. Nature 375(6530):391-4.

Hodell DA, Brenner M, Curtis JH. 2005. Terminal Classic drought in the northern Maya lowlands inferred from multiple sediment cores in Lake Chichancanab (Mexico). Quaternary Science Reviews 24(12-13): 1413-27.

Holzhauser H, Magny M, Zumbuühl HJ. 2005. Glacier and lake-level variations in west-central Europe over the last 3500 years. The Holocene 15(6):789-801.

Hormes A, Müller BU, Schlüchter C. 2001. The Alps 
with little ice: evidence for eight Holocene phases of reduced glacier extent in the Central Swiss Alps. The Holocene 11(3):255-65.

Knox JC. 1999. Sensitivity of modern and Holocene floods to climate change. Quaternary Science Reviews 19(1-5):439-57.

Kutschera W, Müller W. 2003. "Isotope language" of the Alpine Iceman investigated with AMS and MS. $\mathrm{Nu}$ clear Instruments and Methods in Physics Research B 204:705-19.

Lamb HH. 1995. Climate, History and the Modern World. London: Routledge. 464 p.

Le Roy Ladurie E. 1967. Histoire du climat depuis l'an mil. Paris: Flammarion. 287 p. In French.

Li Z, Saito Y, Matsumoto E, Wang Y, Tanabe S, Vu QL. 2006. Climate change and human impact on the Song Hong (Red River) Delta, Vietnam, during the Holocene. Quaternary International 144(1):4-28.

Maasch KA, Mayewski PA, Rohling EJ, Stager JC, Karlén W, Meeker LD, Meyerson EA. 2005. A 2000-year context for modern climate change. Geografiska Annaler A 87(1):7-15.

Magny M. 2004. Holocene climate variability as reflected by mid-European lake-level fluctuations and its probable impact on prehistoric human settlements. Quaternary International 113(1):65-79.

Magny M, Leuzinger U, Bortenschlager S, Haas JN. 2006. Tripartite climate reversal in Central Europe 5600-5300 years ago. Quaternary Research 65(1):319.

Maise C. 1998. Archäoklimatologie - Vom Einfluss nacheiszeitlicher Klimavariabilität in der Ur- und Frúhgeschichte. Jahrbuch der Schweizerischen Gesellschaft für Ur- und Frúhgeschichte 81:197-235. In German.

Mann ME, Bradley RS, Hughes MK. 1999. Northern Hemisphere temperatures during the past millennium: inferences, uncertainties, and limitations. Geophysical Research Letters 26(6):759-62.

Mayewski PA, Meeker LD, Twickler MS, Whitlow S, Yang Q, Lyons WB, Prentice M. 1997. Major features and forcing of high-latitude Northern Hemisphere atmospheric circulation using a 110,000-year-long glaciochemical series. Journal of Geophysical Research 102(C12):26,345-66.

Mayewski PA, Rohling EE, Stager JC, Karlén W, Maasch KA, Meeker LD, Meyerson EA, Gasse F, van Kreveld S, Holmgren K, Lee-Thorp J, Rosqvist G, Rack F, Staubwasser M, Schneider RR, Steig EJ. 2004. Holocene climate variability. Quaternary Research 62(3):243-55.

Neff U, Burns SJ, Mangini A, Mudelsee M, Fleitmann D, Matter A. 2001. Strong coherence between solar variability and the monsoon in Oman between 9 and $6 \mathrm{kyr}$ ago. Nature 411(6835):290-3.

Noren AJ, Bierman PR, Steig EJ, Lini A, Southon J. 2002. Millennial-scale storminess variability in the northeastern United States during the Holocene epoch. Nature 419(6909):821-4.

O'Brien SR, Mayewski PA, Meeker LD, Meese DA, Twickler MS, Whitlow SI. 1995. Complexity of Holocene climate as reconstructed from a Greenland ice core. Science 270(5244): 1962-4.

Peterson LC, Haug GH. 2005. Climate and the collapse of Maya civilization. American Scientist 93(4):322-9.

Raspopov OM, Dergachev VA, Kuzmin AV, Kozyreva OV, Ogurtsov MG, Kolström T, Lopatin E. 2007. Regional tropospheric responses to long-term solar activity variations. Advances in Space Research. doi: 10.1016/j.asr.2007.01.081.

Reid GC. 1987. Influence of solar variability on global sea surface temperatures. Nature 329(6135):142-3.

Renssen H, Goosse H, Fichefet T, Campin J-M. 2001. The 8.2 kyr BP event simulated by a global atmosphere-sea-ice-ocean model. Geophysical Research Letters 28(8):1567-70.

Rind D, Lean J, Healy R. 1999. Simulated time-dependent climate response to solar radiative forcing since 1600. Journal of Geophysical Research 104(D2): 1973-90.

Ristvet L. 2003. Agriculture, settlement, and abrupt climate change: the $4.2 \mathrm{ka} \mathrm{BP}$ event in northern Mesopotamia. Eos, Transactions $A G U$ 84(46). Fall Meeting Supplement, Abstract. F 885.

Rohling EJ, Pälike H. 2005. Centennial-scale climate cooling with a sudden cold event around 8,200 years ago. Nature 434(7036):975-9.

Solanki SK, Fligge M. 1999. A reconstruction of total solar irradiance since 1700. Geophysical Research Letters 26(16):2465-8.

Stager JC, Ryves BF, Cumming BF, Meeker LD, Beer J. 2005. Solar variability and the levels of Lake Victoria, east Africa, during the last millennium. Journal of $\mathrm{Pa}$ leolimnology 33(2):243-51.

Stuiver M, Reimer PJ, Bard E, Beck JW, Burr GS, Hughen KA, Kromer B, McCormac G, van der Plicht J, Spurk M. 1998. IntCa198 radiocarbon age calibration, 24,000-0 cal BP. Radiocarbon 40(3): 1041-83.

Svensmark H, Friis-Christensen E. 1997. Variation of cosmic ray flux and global cloud coverage-a missing link in solar-climate relationships. Journal of Atmospheric and Solar-Terrestrial Physics 59(11):122532.

Svensmark H, Pedersen JOP, Marsh ND, Enghoff MB, Uggerhøj UI. 2007. Experimental evidence for the role of ions in particle nucleation under atmospheric conditions. Proceedings of the Royal Society A 463 (2078):385-96.

Thompson LG, Mosley-Thompson E, Brecher H, Davis M, León B, Les D, Lin P-N, Mashiotta T, Mountain K. 2006. Abrupt tropical climate change: past and present. Proceedings of the National Academy of Sciences USA 103(28): 10,536-43.

van Geel B, Raspopov OM, Renssen H, van der Plicht J, 
Dergachev VA, Meijer HAJ. 1999. The role of solar forcing upon climate change. Quaternary Science Reviews 18(3):331-8.

van Geel B, Bokovenko NA, Burova ND, Chugunov KV, Dergachev VA, Dirksen VG, Kulkova M, Nagler A, Parzinger H, van der Plicht J, Vasiliev SS, Zaitseva GI. 2004. Climate change and expansion of the Scythian culture after 850 BC: a hypothesis. Journal of Archaeological Science 31(12):1735-42.

Vasiliev SS, Dergachev VA. 2002. The $\sim 2400$-year cycle in atmospheric radiocarbon content: bispectrum of ${ }^{14} \mathrm{C}$ data over the last 8000 years. Annales Geophysicae
20(1):115-20.

Verschuren D, Laird KR, Cumming BF. 2000. Rainfall and drought in equatorial east Africa during the past 1,100 years. Nature 403(6768):410-3.

Weber SL, Crowley TJ, van der Schrier G. 2004. Solar irradiance forcing of centennial climate variability during the Holocene. Climate Dynamics 22(5):53953.

Wendland WM, Bryson RA. 1974. Dating climatic episodes of the Holocene. Quaternary Research 4(1):914. 